\title{
Assessment of a new electrocardiographic criterion for the diagnosis of left ventricle hypertrophy: A prospective validation study
}

\author{
(D) Kudret Keskin, (1) Ozgur Selim Ser, (1) Gunes Melike Dogan, (1) Gokhan Cetinkal, \\ (D) Suleyman Sezai Yildiz, (D) Serhat Sigirci, (D) Kadriye Kilickesmez \\ Department of Cardiology, Sisli Hamidiye Etfal Training and Research Hospital, Health Sciences University, Istanbul, Turkey
}

\begin{abstract}
OBJECTIVE: Many criteria have been developed to predict left ventricular hypertrophy using an electrocardiogram (ECG). However, one major common limitation of all has been their low sensitivity. Based on that, recently, a novel criterion has been proposed, which is believed to have higher sensitivity without a compromise in specificity. Therefore, in our study, we aimed to test this novel ECG criterion prospectively in large, unselected cardiac patients.

METHODS: Patients who were referred to our echocardiography laboratory due to various etiologies were prospectively enrolled. The novel Peguero-Lo Presti criterion was assessed along with other established ECG criteria. The left ventricular mass index was calculated using echocardiography. The performance of each index was evaluated.

RESULTS: Overall, 767 patients were enrolled in this study. The sensitivity and specificity of the Peguero-Lo Presti criterion were $\mathbf{1 7 . 5 \%}$ and $\mathbf{9 4 . 5 \%}$, respectively. Although the highest sensitivity belonged to the Peguero-Lo Presti criterion, in ROC analysis, it showed modest predictive capability, which was similar to the established Cornell voltage criterion (AUC=0.64 [0.56-0.68 95\% CI], $\mathrm{p}<0.01)$.

CONCLUSION: Although this novel criterion had higher sensitivity, the overall performance was similar to the current indices. Further adjustments, particularly based on age and body mass index, may yield better results.

Keywords: Electrocardiogram; hypertrophy; left ventricular mass.

Cite this article as: Keskin K, Ser OS, Dogan GM, Cetinkal G, Yildiz SS, Sigirci S, et al. Assessment of a new electrocardiographic criterion for the diagnosis of left ventricle hypertrophy: A prospective validation study. North Clin Istanb 2020;7(3):231-236.
\end{abstract}

E lectrocardiogram (ECG) is still the most widely used tool for screening cardiac abnormalities, in particular, left ventricular hypertrophy ( $\mathrm{LVH}$ ) which is closely related to morbidity and mortality $[1,2]$. Despite its low cost and widespread availability, ECG has many limitations concerning LVH assessment leading to the development of more than 30 different criteria, most of which have only modest sensitivities [3]. However, recently, a new criterion has been proposed by Peguero et al. [4] to identify LVH on ECG. Contrary to the previously described measurements, in which fixed leads are chosen for calculation. This new method incorporates the sum of $\mathrm{S}$ wave amplitude in lead V4 and the highest $\mathrm{S}$ wave in any lead. It is believed that selective measurement of the $S$ wave of the QRS complex combined with the flexible lead selection improves sensitivity without hampering specificity. On the other hand, this new criterion has only been tested in a small number of patients. Thus, it is hard to implement it into clinical practice without validation. Therefore, in our study, we wanted to assess the sensitivity and specificity of

Received: April 03, 2019 Accepted: June 10, 2019 Online: July 09, 2019

Correspondence: Dr. Kudret KESKIN. Sisli Hamidiye Etfal Egitim ve Arastirma Hastanesi, Kardiyoloji Klinigi, Istanbul, Turkey. Tel: +90 5054015847 e-mail: keskinkudret@yahoo.com

(c) Copyright 2020 by Istanbul Provincial Directorate of Health - Available online at www.northclinist.com 
this newly proposed criterion in a larger, unselected, real-world population and compare results with previously established Sokolow-Lyon and Cornell criteria.

\section{MATERIALS AND METHODS}

\section{Patients}

We prospectively enrolled patients who were referred to our echocardiography laboratory due to a wide range of diagnoses. Patients with inadequate acoustic window, pace-maker rhythm and complete bundle branch block were excluded from this study. Ethical board approval was obtained from the institutional review board (Approval number: 1180 , date: 05/03/2019).

\section{Echocardiographic Measurements}

Echocardiography was used to calculate left ventricle (LV) mass using the Devereux formula according to which LVH was described as a left ventricular mass index greater than $115 \mathrm{~g} / \mathrm{m}^{2}$ in male and $95 \mathrm{~g} / \mathrm{m}^{2}$ in female subjects. Devereux formula for left ventricular mass $(\mathrm{g})$ : $0.80 \times\{1.04 \times[($ septal thickness + internal diameter + posterior wall thickness) $3-$ (internal diameter) 3$]\}+0.6$ $\mathrm{g}[5]$. The left ventricular mass was indexed according to body surface area. All echocardiographic measurements were performed by two physicians who had at least a 10-year-experience in cardiology and echocardiography, in accordance with the recommendations of the American Society of Echocardiography [6]. All measurements were recorded in a standardized manner using a Philips iE33 echocardiography machine (Philips, the Netherlands), with a $3 \mathrm{MHz}$ transducer. Frames showing left ventricular end-diastolic diameter, septum, and posterior wall simultaneously were chosen for measurements.

\section{ECG Interpretation}

An electrocardiogram was obtained from each patient on the same day echocardiogram was performed. Standard 12-lead ECGs were recorded in all patients at $1 \mathrm{mV} / 10$ $\mathrm{mm}$ and $25 \mathrm{~mm} / \mathrm{sec}$. calibration and evaluated by two different cardiologists who were blinded to the echocardiographic findings. When assessing the newly proposed Peguero-Lo Presti criterion, the amplitude of the deepest $\mathrm{S}$ wave in any lead was added to the amplitude of the $\mathrm{S}$ wave in lead V4. Cut-off values for hypertrophy were $2.3 \mathrm{mV}$ for women and $2.8 \mathrm{mV}$ for men, respectively. To compare the sensitivity and specificity of this newly proposed method, we also assessed LVH according to
Sokolow-Lyon and Cornell criteria. The Sokolow-Lyon voltage criterion was calculated by adding the amplitude of $S$ wave in lead V1 and the amplitude of $R$ wave in lead $\mathrm{V} 5$ or V6 and values greater than $3.5 \mathrm{mV}$ were considered as LVH [3]. In the limb lead voltage criteria, the amplitude of $\mathrm{R}$ wave in aVL greater than $1.1 \mathrm{mV}$ and amplitude of $\mathrm{R}$ wave in lead D1 greater than $1.4 \mathrm{mV}$ were also considered as LVH. When calculating $\mathrm{LVH}$ according to Cornell criteria, sex-specific cut-off values were applied in which the amplitude of $\mathrm{R}$ wave in lead aVL plus the amplitude of S or QS complex in lead V3 greater than $2.8 \mathrm{mV}$ in men and $2.0 \mathrm{mV}$ in women were considered as $\mathrm{LVH}[3]$.

\section{Statistical Analysis}

Distribution of data was evaluated using the KolmogorovSmirnov test. Continuous variables were reported as means \pm standard deviation, and categorical data were reported as numbers and percentages. Receiver operator characteristics (ROC) analysis was performed to estimate the performance of selected indices and the newly proposed Peguero-Lo Presti criterion. Mc Nemar test was used to evaluate the agreement between the ECG criteria and the left ventricular mass index. Also, Pearson correlation analysis was performed to assess the relationship between LV mass index and ECG voltage amplitude. All statistical analysis was carried out using Statistical Package for the Social Sciences (SPSS) software, version 20.

\section{RESULTS}

Overall, 767 patients were included in the final analysis. The mean age was $51.1 \pm 16.2(18-93)$ and 405 (52.8\%) of them were female. The main indications for echocardiography referral included hypertension ( $\mathrm{n}=169,22 \%)$, ischemic heart disease $(n=238,31 \%)$, valvular heart disease $(n=122,16 \%)$, evaluation of chest pain $(n=191$, $25 \%)$ and other etiologies ( $n=46,6 \%)$. The clinical characteristics and echocardiographic findings are presented in Table 1. The definition of left ventricular hypertrophy was based on the left ventricular mass index calculated based on the Devereux formula derived from echocardiographic measurements. Patients with LVH were older $(61.0 \pm 12.1$ vs $48.9 \pm 16.2 \mathrm{p}<0.01)$ and mostly female $(n=96[62.3 \%]$ vs $n=309$ [50.4\%] $p<0.01)$. Also, co-morbidities, including hypertension, diabetes mellitus, chronic renal insufficiency, ischemic heart disease, were more frequent in patients with left ventricular hy- 
TABLE 1. Clinical characteristics and echocardiographic findings of the study patients

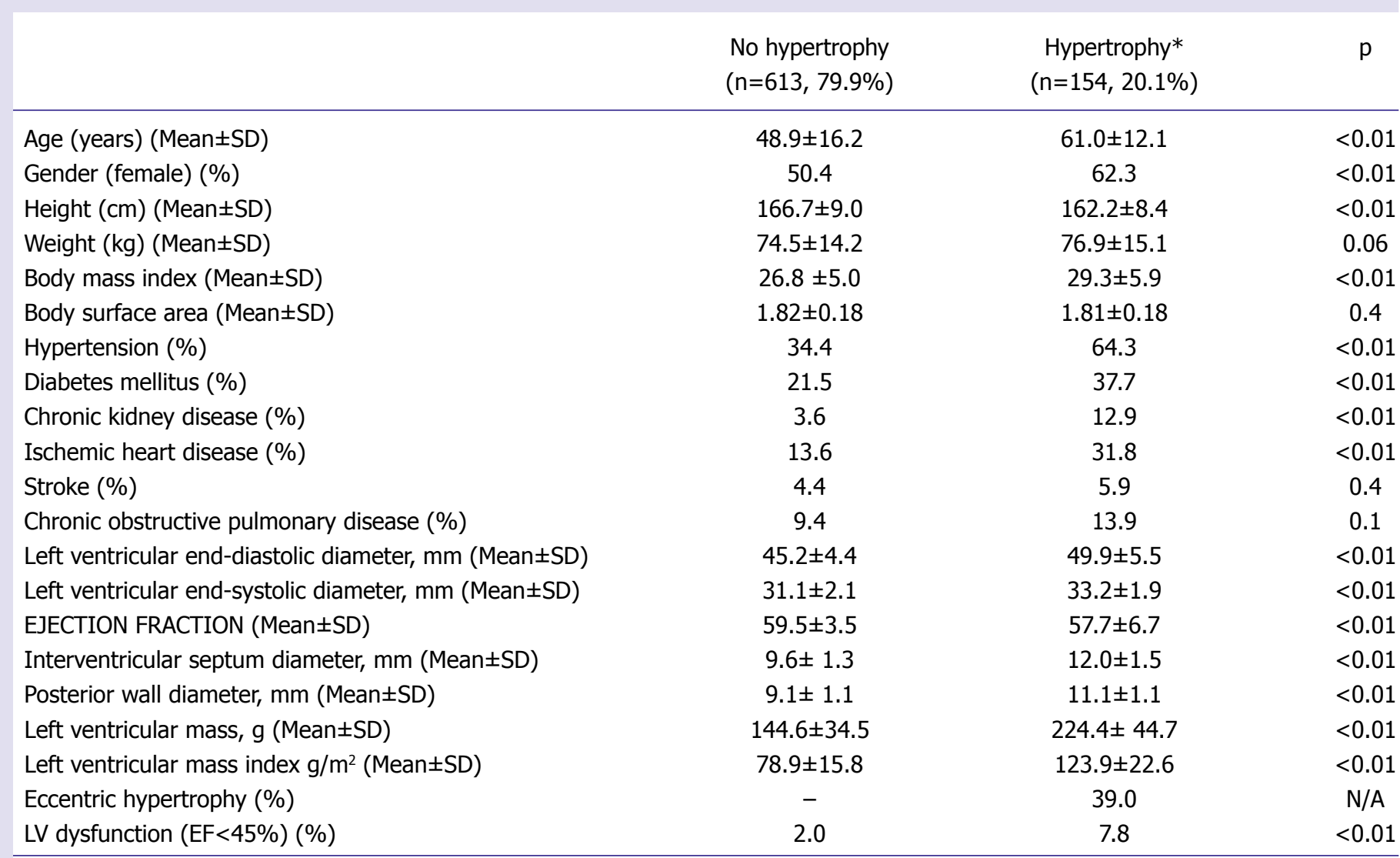

SD: Standard deviation; LV: Left ventricle; * The definition of left ventricular hypertrophy was based on the left ventricular mass index which was calculated based on Devereux formula derived from echocardiographic measurements.

pertrophy. Concerning echocardiographic findings, LV mass and LV mass index were significantly higher in patients with hypertrophy $(224.4 \pm 44.7 \mathrm{~g}$ vs $144.6 \pm 34.5$ g $\mathrm{p}<0.01$ and $123.9 \pm 22.6 \mathrm{~g} / \mathrm{m}^{2}$ vs $78.9 \pm 15.8 \mathrm{~g} / \mathrm{m}^{2}$ $\mathrm{p}<0.01$ respectively). Mean LV ejection fraction was similar in both groups despite having a statistical significance $(57.7 \pm 6.7 \%$ vs $59.5 \pm 3.5 \%, \mathrm{p}<0.01)$. LV systolic dysfunction which was defined as $\mathrm{LVEF}<45 \%$ was more common in patients with LV hypertrophy $(n=12$ [7.8\%] vs $\mathrm{n}=12[2.0 \%], \mathrm{p}<0.01)$.

The sensitivity and specificity of different criteria based on the Mc Nemar test are presented in Table 2. In particular, the sensitivity and specificity of the PegueroLo Presti criterion were $17.5 \%$ and $94.5 \%$, respectively. Among different criteria, while the highest sensitivity belonged to the Peguero-Lo Presti criterion, the highest specificity was seen in RL1 (98.5\%). These analyses were also performed, including only hypertensive patients. The results are presented in Table 3. In general, the sensitiv-
TABLE2. Sensitivity and specificity of each criterion in the entire cohort

$\begin{array}{ll}\text { Sensitivity } & \text { Specificity } \\ (95 \% \mathrm{CI}) & (95 \% \mathrm{CI})\end{array}$

\begin{tabular}{lccc}
\hline RL1 & 5.2 & 98.5 & $<\mathbf{0 . 0 1}$ \\
RaVL & 6.5 & 98.4 & $<\mathbf{0 . 0 1}$ \\
Sokolow-Lyon voltage & 3.9 & 97.6 & $<\mathbf{0 . 0 1}$ \\
Cornell voltage & 9.7 & 98.2 & $<\mathbf{0 . 0 1}$ \\
SD+SV4 (Peguero-Lo Presti) & 17.5 & 94.5 & $<\mathbf{0 . 0 1}$ \\
\hline
\end{tabular}

CI: Confidence intervals; RL1: The voltage of R wave in lead 1; RaVL: The voltage of $\mathrm{R}$ wave in lead V4; SD: The deepest S wave in any lead; SV4: The deepest $\mathrm{S}$ wave in lead $\mathrm{V} 4$.

ities of all criteria increased with accompanying a slight decrease in the specificity. Again, the highest sensitivity and the lowest specificity were seen in the Peguero-Lo Presti criterion (19.2\% and $93.8 \%$ respectively). 
TABLE 3. Sensitivity and specificity of each criterion in hypertensive patients

$\begin{array}{lccc}\mathrm{n}=310 & \begin{array}{r}\text { Sensitivity } \\ (95 \% \mathrm{CI})\end{array} & \begin{array}{c}\text { Specificity } \\ (95 \% \mathrm{CI})\end{array} & \mathrm{p} \\ & 6.1 & 97.6 & <\mathbf{0 . 0 1} \\ \text { RL1 } & 7.1 & 96.7 & <\mathbf{0 . 0 1} \\ \text { RaVL } & 5.1 & 99.5 & <\mathbf{0 . 0 1} \\ \text { Sokolow-Lyon voltage } & 12.1 & 94.8 & <\mathbf{0 . 0 1} \\ \text { Cornell voltage } & 19.2 & 93.8 & <\mathbf{0 . 0 1} \\ \text { SD+SV4 (Peguero-Lo Presti) } & & \end{array}$

CI: Confidence intervals; RL1: The voltage of R wave in lead 1; RaVL: The voltage of $\mathrm{R}$ wave in lead V4; SD: The deepest S wave in any lead; SV4: The deepest $\mathrm{S}$ wave in lead V4.

TABLE 4. Area under curve values of all indices

\begin{tabular}{lcc} 
& AUC value & $\mathrm{p}$ \\
\hline RL1 & 0.63 & $<\mathbf{0 . 0 1}$ \\
RaVL & 0.68 & $<\mathbf{0 . 0 1}$ \\
Sokolow-Lyon voltage & 0.52 & 0.3 \\
Cornell voltage & 0.67 & $<\mathbf{0 . 0 1}$ \\
SD+SV4 (Peguero-Lo Presti) & 0.64 & $<\mathbf{0 . 0 1}$ \\
\hline
\end{tabular}

AUC: Area under curve; CI: Confidence intervals; RL1: The voltage of R wave in lead 1; RaVL: The voltage of $\mathrm{R}$ wave in lead V4; SD: The deepest $\mathrm{S}$ wave in any lead; SV4: The deepest S wave in lead V4.

ROC analysis was also carried out and the results are demonstrated in Table 4 and Figure 1. Peguero-Lo Presti criterion's area under curve (AUC) value was $0.64(0.56-0.6895 \% \mathrm{CI}, \mathrm{p}<0.01)$. While the highest AUC value was seen in RaVL criterion $(A U C=0.68$, [0.63-0.72 95\% CI], p<0.01), Sokolow-Lyon voltage criterion did not reach a statistical significance (AUC $=0.52,[0.47-0.57$ 95\% CI], p=0.3). Pearson correlation analysis showed a weak correlation between LV mass index and Peguero-Lo Presti measurements $(\mathrm{r}=0.3, \mathrm{p}<0.01)$.

\section{DISCUSSION}

In our study, although the sensitivity of the novel Peguero-Lo Presti criterion was higher compared to other indices, the overall predictive performance was modest and similar to that of the Cornell voltage criterion. There was also a weak correlation between LV mass

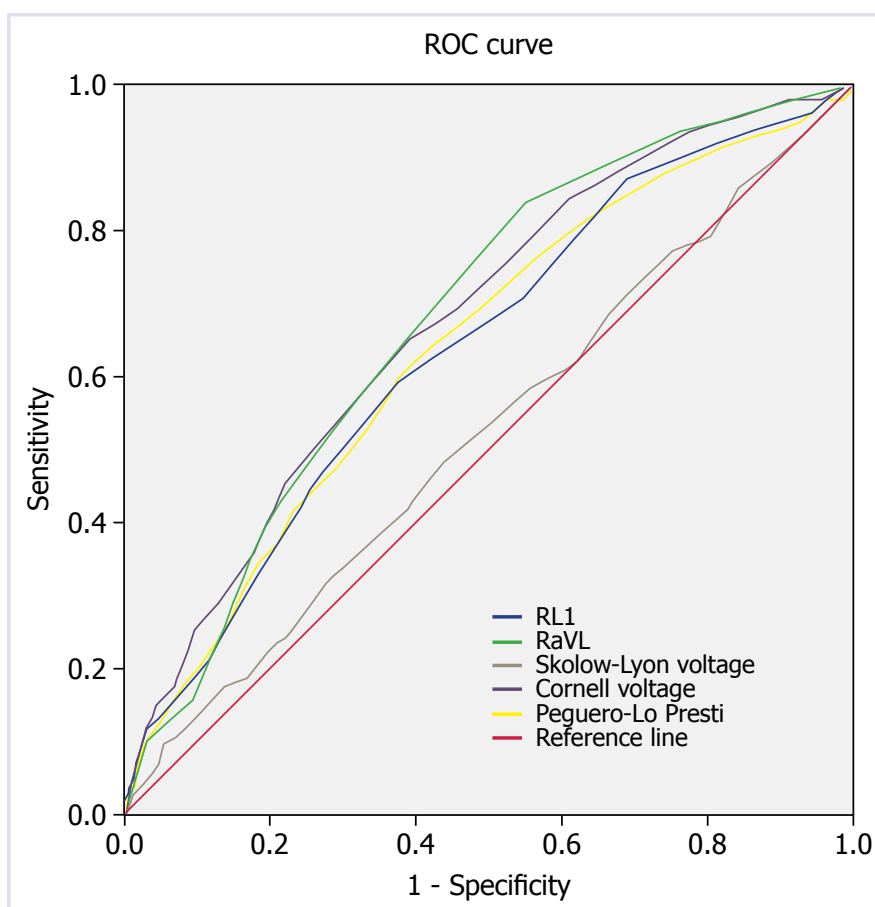

FIGURE 1. ROC analysis showing area under curve values of each index including the novel Peguero-Lo Presti criterion.

ROC: Receiver operating characteristics.

index and ECG voltage amplitude. On the other hand, the Sokolow-Lyon voltage criterion showed the worst sensitivity and specificity based on the ROC analysis.

This novel ECG criterion emerged based on two distinct premises: improvement in the overall accuracy of LVH prediction due to the flexibility of any lead selection since fixed lead selection overlooks the position of the heart within the thorax and adjacent structures. Alterations in the distance of the left ventricular cavity to the electrode, the position of the surface electrode, and anthropometric differences are all considered as the major limitations of fixed lead selection [7]. The other hypothesis was based on the temporal multiple wavefront changes within the left ventricle during depolarization in which myocardial and epicardial LV free wall activation occur after the first $50 \mathrm{msec}$ and thus better represented with the $\mathrm{S}$ wave of the QRS complex [4].

Despite these two promising hypotheses, we did not find the superiority of this new index compared to standard indices. First of all, the low sensitivity of ECG has long been acknowledged in the literature [8]. For example, in the Framingham Heart Study, the sensitivity of the gender-specific Cornell voltage criterion was only $10 \%$ in men and $22 \%$ in women. In the PIUMA study, it was $12 \%$ 
in men and $19 \%$ in women, respectively $[9,10]$. Likewise, the prevalence of LVH detected by ECG using the Framingham method (voltage criteria with "strain pattern") was only $2 \%$ in the general population [11]. The inherent limitation of ECG to detect LVH accurately is related to many factors. First, ECG relies on the electrical activity of the myocardium; however, alterations in the interstitium such as fibrosis and deposition of other materials lower the voltage expression, which limits the ECG to detect LVH [12]. Second, when measuring voltage changes, several confounding factors, such as age, sex, body habitus, and race, affect the reliability of these measurements, which are not truly addressed in the ECG indices [13].

Given the aforementioned limitations of ECG, there are also significant differences in our cohort compared to the original test study conducted by Peguero et al. First, the original study was retrospective in design, which comprised 94 tests and 130 validation patients, whereas our prospective cohort was much larger. Second, the original study was based on highly selected hypertensive patients who were admitted to the hospital. Our cohort included patients who were referred to the echocardiography lab due to different etiologies. Therefore, our cohort comprised of unselected general outpatients. The number of patients enrolled, their baseline clinical and echocardiographic differences might have played a role in the accuracy of the newly developed criterion.

One other important factor that attenuates the predictive capability of ECG to detect hypertrophy is the geometry of LV. There are data showing that concentric $\mathrm{LVH}$ is more accurately detected by ECG compared to eccentric LVH, which might contribute to our study results in which $39 \%$ of the LVH were eccentric [14].

Since the publication of the Peguero-Lo Presti criterion, many big-scale validation studies were conducted with different outcomes. Sun GZ et al. [15] assessed the Peguero-Lo Presti criterion in approximately 10.000 Asian patients and concluded that the novel PegueroLo Presti voltage might not be better for screening LVH in Asians. (AUC: 0.66 for males, AUC: 0.68 for females). LD Ha et al. [16] compared the major electrocardiogram indices for $\mathrm{LVH}$, including novel PegueroLo Presti criterion to predict cardiovascular mortality, as a surrogate for pathological hypertrophy and found Peguero-Lo Presti criterion to be inferior for predicting cardiovascular mortality to the original Cornell index. Recently, Clark E assessed Peguero-Lo Presti criterion in some 1500 apparently healthy individuals and found the specificity of the new Peguero-Lo Presti criterion to be quite poor in younger people $<30$ years), being only $50 \%$ males and $76 \%$ in females, and therefore offered this novel criterion to be age and sex-adjusted [17]. In fact, the authors of the Peguero-Lo Presti criterion have already declared that they were currently in the process of assessing further the accuracy of this novel criterion after adjustment for the aforementioned variables [18].

\section{Limitations}

Magnetic resonance imaging, which is the gold standard for LV mass calculation, was not performed in our study [7]. However, we believe that our results are still valid since echocardiogram is used to guide the treatment in the vast majority of patients and also it would be impractical to use magnetic resonance imaging in a big prospective validation study. Finally, this was a single-center study. Thus, the results may not be applicable across a broader population and ethnicity.

\section{Conclusion}

Although the novel Peguero-Lo Presti criterion had the highest sensitivity compared to standard indices, it did not outperform the established Cornell or other limb criteria even when evaluated only in hypertensive patients. Age and body mass index-adjusted formulas may yield better results. However, the historical Sokolow-Lyon criterion has not shown to be predictive of $\mathrm{LVH}$ in our cohort, probably related to baseline clinical characteristics.

Ethics Committee Approval: Sisli Hamidiye Etfal Training and Research Hospital Clinical Research Ethics Committee granted approval for this study (date: 05.03.2019, number: 1180).

Conflict of Interest: No conflict of interest was declared by the authors.

Financial Disclosure: The authors declared that this study has received no financial support.

Authorship Contributions: Concept - KK, OSS; Design - KK, SS, OSS; Supervision - SSY; Materials - OSS, GMD; Data collection and/ or processing - OSS, GMD; Analysis and/or interpretation - GC, SS; Writing - KK; Critical review - KaK.

\section{REFERENCES}

1. Bluemke DA, Kronmal RA, Lima JA, Liu K, Olson J, Burke GL, et al. The relationship of left ventricular mass and geometry to incident cardiovascular events: the MESA (Multi-Ethnic Study of Atherosclerosis) study. J Am Coll Cardiol 2008;52:2148-55. [CrossRef]

2. Mahn JJ, Dubey E, Brody A, Welch R, Zalenski R, Flack JM, et al. Test characteristics of electrocardiography for detection of left ventricular 
hypertrophy in asymptomatic emergency department patients with hypertension. Acad Emerg Med 2014;21:996-1002. [CrossRef]

3. Hancock EW, Deal BJ, Mirvis DM, Okin P, Kligfield P, Gettes LS, et al; American Heart Association Electrocardiography and Arrhythmias Committee, Council on Clinical Cardiology; American College of Cardiology Foundation; Heart Rhythm Society. AHA/ACCF/HRS recommendations for the standardization and interpretation of the electrocardiogram: part V: electrocardiogram changes associated with cardiac chamber hypertrophy: a scientific statement from the American Heart Association Electrocardiography and Arrhythmias Committee, Council on Clinical Cardiology; the American College of Cardiology Foundation; and the Heart Rhythm Society. Endorsed by the International Society for Computerized Electrocardiology. J Am Coll Cardiol 2009;53:992-1002.

4. Peguero JG, Lo Presti S, Perez J, Issa O, Brenes JC, Tolentino A. Electrocardiographic Criteria for the Diagnosis of Left Ventricular Hypertrophy. J Am Coll Cardiol 2017;69:1694-703. [CrossRef]

5. Lang RM, Bierig M, Devereux RB, Flachskampf FA, Foster E, Pellikka PA, et al; Chamber Quantification Writing Group; American Society of Echocardiography's Guidelines and Standards Committee; European Association of Echocardiography. Recommendations for chamber quantification: a report from the American Society of Echocardiography's Guidelines and Standards Committee and the Chamber Quantification Writing Group, developed in conjunction with the European Association of Echocardiography, a branch of the European Society of Cardiology. J Am Soc Echocardiogr 2005;18:1440-63. [CrossRef]

6. Lang RM, Badano LP, Mor-Avi V, Afilalo J, Armstrong A, Ernande L, et al. Recommendations for cardiac chamber quantification by echocardiography in adults: an update from the American Society of Echocardiography and the European Association of Cardiovascular Imaging. Eur Heart J Cardiovasc Imaging 2015;16:233-70. [CrossRef]

7. Bacharova L, Ugander M. Left ventricular hypertrophy: The relationship between the electrocardiogram and cardiovascular magnetic resonance imaging. Ann Noninvasive Electrocardiol 2014;19:524-33. [CrossRef]

8. Pewsner D, Jüni P, Egger M, Battaglia M, Sundström J, Bachmann LM.
Accuracy of electrocardiography in diagnosis of left ventricular hypertrophy in arterial hypertension: systematic review. BMJ 2007;335:711.

9. Levy D, Labib SB, Anderson KM, Christiansen JC, Kannel WB, Castelli WP. Determinants of sensitivity and specificity of electrocardiographic criteria for left ventricular hypertrophy. Circulation 1990;81:815-20.

10. Schillaci G, Verdecchia P, Borgioni C, Ciucci A, Guerrieri M, Zampi I, et al. Improved electrocardiographic diagnosis of left ventricular hypertrophy. Am J Cardiol 1994;74:714-9. [CrossRef]

11. Verdecchia P, Schillaci G, Borgioni C, Ciucci A, Gattobigio R, Zampi I, et al. Prognostic value of a new electrocardiographic method for diagnosis of left ventricular hypertrophy in essential hypertension. J Am Coll Cardiol 1998;31:383-90. [CrossRef]

12. Bacharova L. Electrocardiography-left ventricular mass discrepancies in left ventricular hypertrophy: electrocardiography imperfection or beyond perfection?. J Electrocardiol 2009;42:593-6. [CrossRef]

13. Jingi AM, Noubiap JJ, Kamdem P, Kingue S. Determinants and improvement of electrocardiographic diagnosis of left ventricular hypertrophy in a black African population. PLoS One 2014;9:e96783. [CrossRef]

14. Tomita S, Ueno H, Takata M, Yasumoto K, Tomoda F, Inoue H. Relationship between electrocardiographic voltage and geometric patterns of left ventricular hypertrophy in patients with essential hypertension. Hypertens Res 1998;21:259-66. [CrossRef]

15. Sun GZ, Wang HY, Ye N, Sun YX. Assessment of Novel Peguero-Lo Presti Electrocardiographic Left Ventricular Hypertrophy Criteria in a Large Asian Population: Newer May Not Be Better. Can J Cardiol 2018;34:1153-7. [CrossRef]

16. Ha LD, Elbadawi A, Froelicher VF. Limited Relationship of Voltage Criteria for Electrocardiogram Left Ventricular Hypertrophy to Cardiovascular Mortality. Am J Med 2018;131:101.e1-101.e8. [CrossRef]

17. Clark E, MacFarlane PW. Specificity of new diagnostic criteria for left ventricular hypertrophy. Comput Cardiol 2010 2017;44:1-4. [CrossRef]

18. Peguero JG, Lo Presti S, Perez J, Issa O, Brenes JC, Tolentino A. Reply: Adjustments of Electrocardiographic Criteria for the Diagnosis of Left Ventricular Hypertrophy. J Am Coll Cardiol 2017;70:687. [CrossRef] 